
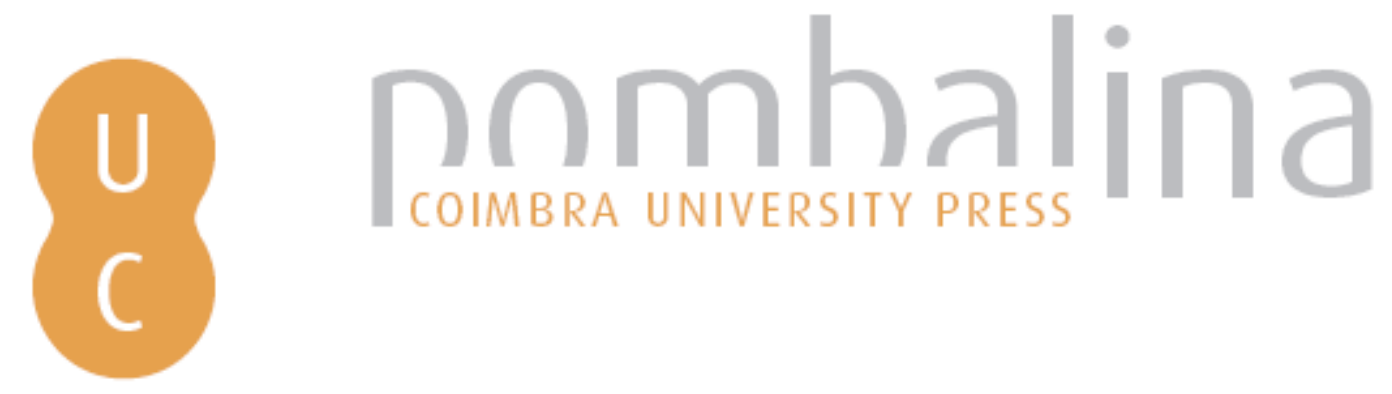

\title{
Capacitação de mediadores no uso do acervo das Minibibliotecas da Embrapa no âmbito dos Territórios da Cidadania no semiárido brasileiro
}

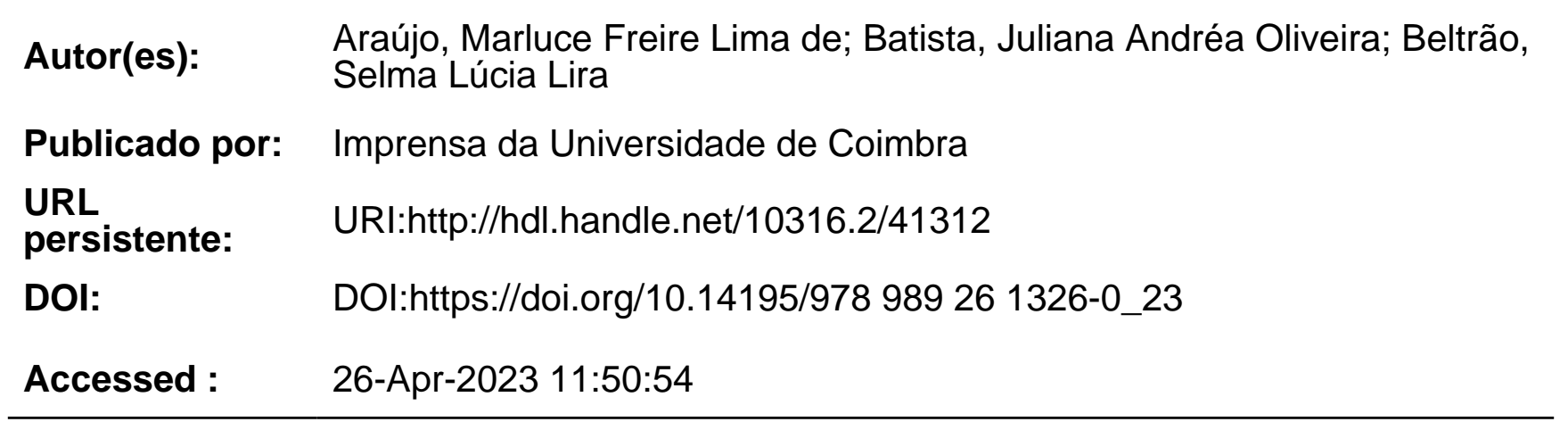

A navegação consulta e descarregamento dos títulos inseridos nas Bibliotecas Digitais UC Digitalis, UC Pombalina e UC Impactum, pressupõem a aceitação plena e sem reservas dos Termos e Condições de Uso destas Bibliotecas Digitais, disponíveis em https://digitalis.uc.pt/pt-pt/termos.

Conforme exposto nos referidos Termos e Condições de Uso, o descarregamento de títulos de acesso restrito requer uma licença válida de autorização devendo o utilizador aceder ao(s) documento(s) a partir de um endereço de IP da instituição detentora da supramencionada licença.

Ao utilizador é apenas permitido o descarregamento para uso pessoal, pelo que o emprego do(s) título(s) descarregado(s) para outro fim, designadamente comercial, carece de autorização do respetivo autor ou editor da obra.

Na medida em que todas as obras da UC Digitalis se encontram protegidas pelo Código do Direito de Autor e Direitos Conexos e demais legislação aplicável, toda a cópia, parcial ou total, deste documento, nos casos em que é legalmente admitida, deverá conter ou fazer-se acompanhar por este aviso.

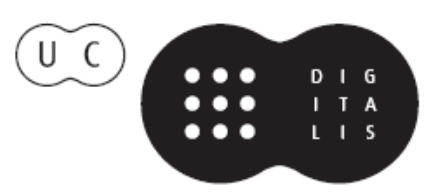




\title{
23. CAPACITAÇÃO DE MEDIADORES NOUSO DO ACERVO DAS MINIBIBLIOTECAS DA EMBRAPA NOÂMBITO DOS TERRITÓRIOS DA CIDADANIA NO S EM I ÁRIDO B RASILEIRO
}

\author{
Marluce Freire Lima de Araújo 118 \\ Juliana Andréa Oliveira Batista 119 \\ Selma Lúcia Lira Beltrão 120
}

\begin{abstract}
Resumo
Este trabalho objetiva socializar a experiência de capacitação de mediadores no uso das Minibibliotecas da Embrapa, ação realizada nos territórios da cidadania do Semiárido brasileiro, no âmbito do Plano Brasil Sem Miséria (PBSM). O projeto Minibibliotecas é uma iniciativa governamental cujo objetivo principal é estimular a prática de leitura e a inclusão produtiva no meio rural, mediante a disponibilização de informações tecnológicas, personalizadas, em linguagem e estilo simples, acessível, com recursos lúdicos, editadas em cartilhas, livros e materiais audiovisuais. Foi idealizada para escolas públicas e privadas
\end{abstract}

118 Pedagoga, Mestre em Extensão Rural. Embrapa Informação Tecnológica.

119 Pedagoga, Mestre em Educação do Campo. Embrapa Informação Tecnológica.

120 Jornalista, Mestre em Política e Gestão de Ciência e Tecnologia. Embrapa Informação Tecnológica. 
do meio rural, escolas agrotécnicas e comunidades rurais, pela identificação de temas e tecnologias de fácil aplicação e baixo custo, capazes de contribuir com as práticas agrícolas sustentáveis, a segurança alimentar e a qualidade de vida no campo. A construção da metodologia dessa ação resultou de experiências piloto no Distrito Federal e, posteriormente, de oficinas realizadas nos territórios do PBSM. A base da metodologia é a pesquisa qualitativa, mediada pelas histórias de vida. Os dados resultaram da aplicação de instrumento de avaliação após cada capacitação, com resultados numéricos e depoimentos destacados pelos participantes. Consideramos que as capacitações têm atendido as expectativas da Embrapa e principalmente de cada participante, potencial multiplicador da metodologia.

\begin{abstract}
This paper aims to share the experience of training mediators to use Small Libraries offered by Embrapa, an initiative which takes place in the citizenship territories of Brazilian semi-arid regions as part of the Brasil sem Miséria Plan (PBSM - Brazil Without Extreme Poverty Plan). The project of the Small Libraries is a governmental initiative wich aims to foster reading habits among people of rural areas and, also, to promote their productive inclusion by offering customized technological information written in simple and easy-to-follow language and style along with ludic resources - all available in booklets, books and audiovisual materials. The project was designed for public and private rural schools, agrotechnical colleges and rural communities, because it comprises themes and easy-to-apply and low-cost technologies that may contribute to the achievement of sustainable agricultural practices, food safety and quality of life in rural areas. The methodology applied resulted from pilot experiences carried out
\end{abstract}


in the Federal District of Brazil and workshops that took place in the PBSM territories. The methodology is based on qualitative research by collecting life stories. Data were collected through assessment documents applied after each training course, which included numeric results and participants' reports. We conclude that training courses have been fulfilling the expectations not only of the Embrapa, but mainly of each participant, which is a potential multiplier of the methodology. 


\section{Introdução}

A Empresa Brasileira de Pesquisa Agropecuária (Embrapa) tem a missão de "viabilizar soluções de pesquisa, desenvolvimento e inovação para a sustentabilidade da agricultura, em benefício da sociedade brasileira”. A Embrapa Informação Tecnológica (SCT) é a Unidade de serviços da Embrapa responsável pela gestão e organização da informação produzida nas unidades da Empresa, por meio de diversas iniciativas editoriais, disponibilizadas em formatos diversos (mídia impressa e mídia eletrônica). O acervo das Minibibliotecas é multimídia. Seus conteúdos e formatos foram estruturados para contribuir com o estímulo à leitura entre jovens rurais e outros sujeitos do campo, apoiar os projetos didático- pedagógicos e/ou comunitários e contribuir com a inclusão social e produtiva, à segurança alimentar, nutricional e ambiental (Embrapa, 2008a).

\section{O Projeto Minibibliotecas}

O Projeto Minibibliotecas é uma iniciativa do SCT em parceria com o Ministério do Desenvolvimento Social e Combate à Fome (MDS), criado em 2003 como uma das ações da Embrapa em contribuição ao programa Fome Zero ${ }^{121}$, e que teve início no Semiárido do Nordeste e Vale do Jequitinhonha - MG. O principal objetivo do projeto é estimular a leitura e a inclusão produtiva no meio rural, a partir da leitura e discussão sobre tecnologias de baixo custo, contextualizadas de acordo com a realidade dos agricultores fami-

121 O Fome Zero, que inicialmente denominou-se como um programa, é uma estratégia conformada por um conjunto de programas, projetos e ações de diversos órgãos do Governo Federal, que visa assegurar o direito humano à alimentação adequada, por meio do acesso aos alimentos e à inclusão social (FOME ZERO, 2006). 
liares. Até o final de 2014, mais de cinco mil entidades (escolas, comunidades de agricultores familiares, assentamentos, sindicatos de trabalhadores rurais, etc.), localizadas em todas as regiões do Brasil, foram beneficiadas com as Minibibliotecas.

Em novembro de 2008, foi realizada uma pesquisa-ação em 122 escolas localizadas nos nove estados da região Nordeste e no Vale do Jequitinhonha - MG. Os dados da pesquisa permitiram compreender especificidades dos contextos locais onde as Minibibliotecas estavam instaladas, bem como identificar pontos fracos e fortes e a oportunidade de melhoria do projeto. A pesquisa-ação encontrou cenários com grande diversidade de experiências, indicando a necessidade de criação de um projeto de capacitação para mediadores no uso das Minibibliotecas. Dessa forma, a estrutura do projeto de capacitação foi se desenhando, no período de 2010 a 2012, por meio de experiências piloto no Distrito Federal, especialmente com profissionais da extensão rural, professores, alunos, agricultores e colegas das áreas de transferência de tecnologia da Embrapa.

\section{As Minibibliotecas no contexto do Plano Brasil Sem Miséria}

O Plano Brasil Sem Miséria (PBSM) é um plano governamental articulado em três eixos: um de garantia de renda, para alívio imediato da situação de extrema pobreza; outro de acesso a serviços públicos, para melhorar as condições de educação, saúde e cidadania das famílias; e um terceiro de inclusão produtiva, para aumentar as capacidades e as oportunidades de trabalho e geração de renda entre as famílias mais pobres do campo e das cidades. Seu principal objetivo é o de acabar com a miséria extrema no Brasil.

Chamada a apoiar o Plano, a Embrapa passou a atuar diretamente no eixo da inclusão produtiva rural, com um conjunto de ações 
focadas no Semiárido brasileiro, contribuindo com o aumento da capacidade e da oportunidade de produção de alimentos e renda, de forma segura e sustentável pelos agricultores familiares.

O SCT ficou responsável pelo projeto de capacitação de mediadores ${ }^{122}$, tendo como primeiro eixo, apoiar as ações de inclusão produtiva em desenvolvimento nos municípios dos 14 territórios da cidadania ${ }^{123}$ priorizados pelo PBSM. O segundo eixo dessa capacitação é contribuir com a melhoria dos sistemas produtivos dos agricultores familiares, com vistas ao fortalecimento da participação desses nas políticas públicas locais de segurança alimentar, inclusão produtiva e geração de renda, a exemplo da compra direta de produtos da agricultura familiar pelo Programa de Aquisição de Alimentos (PAA) ${ }^{124}$ do Ministério do Desenvolvimento Social (MDS), bem como pelo Programa Nacional de Alimentação Escolar (PNAE) ${ }^{125}$ do Ministério da Educação (MEC).

O terceiro eixo é a importância da prática da leitura para os processos emancipatórios dos sujeitos do campo. O incentivo à prática diária da leitura e das práticas sociais nas discussões sobre o uso das Minibibliotecas nos contextos locais é imprescindível, e considerado a mola propulsora para o desenvolvimento das ações esperadas a partir do uso do acervo.

122 Mediador - Pessoa que pode estimular o uso do acervo pela comunidade local (Capacitação de mediadores para uso do acervo das minibiliotecas, 2012).

123 O Programa Territórios da Cidadania foi lançado em 2008 com o objetivo de articular políticas públicas nos territórios rurais pertencentes ao programa. (Portal da cidadania, 2009).

124 O objetivo do PAA é garantir o acesso aos alimentos em quantidade, qualidade e regularidade necessárias às populações em situação de insegurança alimentar e nutricional e promover a inclusão social no campo por meio do fortalecimento da agricultura familiar.

125 O PNAE pretende contribuir com o crescimento, desenvolvimento, aprendizagem, rendimento escolar dos estudantes e a formação de hábitos alimentares saudáveis, por meio da oferta da alimentação escolar e de ações de educação alimentar e nutricional. 


\section{Estrutura pedagógica da oficina de capacitação de mediadores}

Capacitar vem do latim capacitas que nos remete a amplidão. No contexto das Minibibliotecas, busca-se promover de alguma forma a amplidão da visão de mundo do homem/sujeito no seu processo de formação. A capacitação tem uma proposta de educação não formal que, de acordo com Gogh (2006), designa um processo de aprendizagem com dimensões políticas dos direitos do indivíduo enquanto cidadão e pela leitura de mundo do ponto de vista da compreensão do que se passa ao seu redor.

Nas capacitações são utilizadas "Rodas de Conversa" como estratégia e instrumento de pesquisa. Como instrumento de pesquisa, caracteriza-se como uma conversa em um ambiente propício para o diálogo, em que todos se sintam à vontade para partilhar e escutar, de modo que o conversado seja relevante para o grupo e suscite, inclusive, a atenção na escuta onde os vários interlocutores se agregam. Normalmente os momentos de escuta são mais numerosos do que os de fala. As colocações de cada participante são construídas por meio da interação com o outro, seja para complementar ou discordar, seja para concordar com a fala imediatamente anterior. Conversar, nessa acepção, significa compreender com mais profundidade, refletir mais e ponderar, no sentido de socializar, como assim partilha Warschauer (2001).

Como recurso as "Rodas de Conversa" possibilitam discussões em torno de uma temática, promovendo um maior intercâmbio de informações, possibilitando fluidez de discursos e de negociações diversas entre pesquisadores e participantes. No caso das Minibibliotecas se constituem em espaços dialógicos que estimulam a reflexão sobre a importância da leitura dos conteúdos em todos os espaços sociais que fazem parte do cotidiano de cada sujeito envolvido. Esse recurso ganha importância nos contextos 
sociais locais por meio de leituras estruturadas com objetivos e estratégias segmentadas para aquele público específico.

A oficina se inicia com a autoapresentação dos participantes, pautada em metodologia qualitativa, com ênfase no método de História de Vida, que, de acordo com Goldenberg (2000) destaca:

A história de vida como ciência é um conjunto organizado de conhecimentos relativos a um determinado objeto, obtido através da observação e da experiência; (...) é um corpo de conhecimentos sistemáticos, adquiridos com um método próprio, em um determinado meio e momento (p. 103).

No caso das capacitações os mediadores iniciam o diálogo sugerindo a cada participante da roda de conversa que "conte-nos sua história”! A partir de cada história, vai-se configurando uma teia polifônica e representativa que imerge no contexto da história de vida pessoal, local e territorial ao qual pertencem. A partir desse constructo se inicia a mediação, com estratégias desenhadas para os sujeitos de acordo com as suas realidades. Esse começo é fundamental para uma conversa viva, dinâmica, interativa e dialógica.

\section{A capacitação: Roteiro de apresentação do acervo}

Essa atividade consiste em apresentar as coleções impressas e audiovisuais que compõem o acervo das Minibibliotecas. Ao apresentar o acervo para os mediadores é como se de fato começasse ali uma grande celebração, já que é sempre uma alegria, uma vez que se vê, nesse momento, um processo de construção e desconstrução com base nos saberes locais de cada grupo de sujeitos, na prática e na vivência com as culturas alimentares e criações presentes nos 
audiovisuais, além da imensa diversidade cultural e de inúmeros desejos e méritos de pertencimento de cada grupo.

O sujeito não é apenas ativo, mas interativo, porque constitui conhecimento através de relações intra e interpessoais. É na troca com outros sujeitos e consigo próprio que há internalização de conhecimentos, papéis e funções sociais, constituição de conhecimentos e de consciência, embora haja certas áreas em que esses sujeitos nunca conseguirão modificar nosso jeito de pensar (Vygotsky, 1991).

A organização do espaço pedagógico da roda de conversa é sempre em formato circular por entendermos que o mesmo proporciona uma igualdade de pertença, ou seja, todos têm o mesmo lugar de fala, que segundo Orlandi (2013, p. 01), "ao falar, o sujeito constitui um sentido e constitui a si próprio, em um processo de formação da identidade na relação com a língua" e no emprego dela no processo de informação e consequente formação.

Como objeto de todo esse cenário, o kit das Minibibliotecas é formado por um acervo pequeno e complexo composto pelas coleções e outros títulos relacionadas a seguir, cujas temáticas são selecionadas de acordo com o perfil agrícola de cada região.

\section{Coleção 500 Perguntas 500 Respostas}

Essa coleção tem como objetivo suprir os diferentes produtores com informações e explicações, de forma clara e objetiva, a partir de perguntas e respostas, agrupadas em torno de assuntos específicos de espécie animal ou vegetal, ou do sistema de produção analisado. As perguntas foram formuladas por produtores, associações de produtores, cooperativas, entre outros, e respondidas pelas Unidades de pesquisa da Embrapa. É uma coleção composta por títulos impressos, e-books e PDF para download. 
A apresentação dessa coleção nas capacitações se inicia pela contextualização do título, explicando a sua importância, abrangência, os possíveis aprofundamentos em cada aspecto do sistema de produção, seja animal ou vegetal. Segue com a leitura do sumário, e ao mesmo tempo remete-se ao capítulo em questão. Essa coleção hoje é muito utilizada pelas escolas agrotécnicas (institutos federais de educação tecnológica, escolas famílias agrícolas, cursos de graduação em agrárias de modo geral) além de extensionistas agrários e agricultores.

\section{Coleção Agroindústria Familiar}

Contém informações sobre processamento industrial de produtos agropecuários, como leite, frutas, hortaliças, cereais, leguminosas, entre outros, para redução de custos, aumento da renda do produtor e garantia da qualidade do produto final, assegurados pelas boas práticas de fabricação ou de beneficiamento.

Essa coleção é trabalhada de acordo com o contexto territorial, levando muito em consideração a real situação da produção e o seu consequente excedente, seja para venda in natura e/ou processado. $\mathrm{Na}$ apresentação dessa coleção chama-se a atenção para cuidados na manipulação dos alimentos e boas práticas de fabricação - BPF. Esses cuidados visam evitar a contaminação e a perda de qualidade dos gêneros alimentícios, e preservar seu sabor e outras características inerentes. Tais cuidados vão desde o recebimento da matéria-prima até o consumo propriamente dito e, portanto, é importante uma abordagem, ainda que resumida, sobre os aspectos pertinentes a todo o processo de produção de alimentos, de modo que as merendeiras, donas de casa e público em geral possam ter uma noção dos padrões mínimos de controle de qualidade. Recomenda-se que, em caso de dúvidas, procurem profissionais na região que possam acompanhar o processo. 


\section{Coleção ABC da Agricultura Familiar}

As principais características dessa coleção são o uso de linguagem simples, letras com fonte de maior tamanho para facilitar a leitura, com fotografias e /ou ilustrações objetivas, no formato passo a passo. Para a apresentação das publicações dessa coleção destaca-se como produzir com tecnologia de baixo custo e adaptadas aos meios disponíveis na propriedade para temas como: criação de animais, técnicas de plantio, práticas de controle de pragas e doenças, adubação alternativa, fabricação de conservas de frutas, formas de garantir água na seca, além de outros assuntos.

\section{Coleção Plantar}

Traz informações atualizadas sobre cada etapa de cultivo da espécie em foco. As informações são apresentadas de maneira didática e apresenta temas como: hortaliças, fruteiras, plantas medicinais, condimentos, especiarias, oleaginosas, entre outros.

\section{Coleção Saber}

Esta coleção oferece orientações sobre cada uma das etapas necessárias ao desenvolvimento de determinado processo para a obtenção de produtos de qualidade. As informações são apresentadas em linguagem didática, de modo que o leitor possa compreendê-las facilmente e aplicá-las com sucesso em seu empreendimento. As informações tem um caráter mais técnico e por isso mais densas, porém de boa compreensão. Seu uso é mais sugerido para professores, extensionistas e estudantes. 


\section{Coleção Criar}

O objetivo é suprir o leitor de informações sobre cada etapa de criação da espécie animal de grande, médio e pequeno porte, ou sobre os passos a serem seguidos para a obtenção do produto pretendido. Apresenta técnicas e processos que podem ser empregados em negócios agrícolas ou agroindustriais.

Normalmente sugere-se que os mediadores leiam com atenção as orientações apresentadas nessas coleções, respeitando as medidas tanto do espaçamento das covas bem como das quantidades sugeridas de adubos e, visualize bem as ilustrações. Ressalta-se que essas coleções destinam-se a pessoas que já possuem conhecimento técnico mais aprofundado, a exemplo dos técnicos da extensão rural, de estudantes de cursos técnicos de agropecuária, entre outros.

\section{Títulos Infantojuvenis}

Os livros infantojuvenis se propõem a promover o desenvolvimento, a criatividade, a imaginação, a cultura, assim como conhecimentos e valores fundamentais para a formação desse público, considerando que o hábito da leitura em todas as fases da vida ajuda a despertar o senso crítico. Esses títulos integram processos de educação não formal, provenientes de uma instituição pública de pesquisa, com políticas de educação formal, a exemplo da educação ambiental, visando atender às necessidades complementares de crianças e jovens com informações que farão parte da construção do conhecimento para o processo de ensino e aprendizagem desses estudantes da educação básica.

Esses títulos podem atender a vários propósitos da educação básica de acordo com Parâmetros Curriculares Nacionais (PCN’s), nas áreas de linguagens, ciências da natureza, ciências humanas, 
de forma transversal e/ou transdisciplinar em todos os conteúdos, sendo, portanto, apresentadas diversas possibilidades de uso dessas publicações em atividades extracurriculares e nas comunidades como forma de ativar o debate sobre as questões ambientais, estimular o resgate do folclore local, por meio de contos, ou mesmo de histórias reais que tenham relação com a abordagem apresentada nessas publicações.

\section{Série Educação e Cidadania}

Esta série é resultado da parceria entre a Prefeitura Municipal de Patos de Minas - MG e a Embrapa SCT. A educação para a cidadania busca promover a consciência da transformação por meio de ações educativas simples, mas que exige reflexões que possibilitam compreender o contexto em que vivem e buscar soluções coletivas para tornar a vida no campo mais harmônica e produtiva com enfoque na cidadania da família que vive no campo.

Quanto ao uso dessas publicações, como podem ser trabalhados também na educação básica de acordo com PCN’s sugere-se aplicá-las nas áreas de linguagens, ciências da natureza, ciências humanas e de forma transversal e/ou interdisciplinar em todos os conteúdos.

\section{CD-ROM do programa radiofônico Prosa Rural}

Os áudios do programa radiofônico semanal da Embrapa abordam tecnologias de baixo custo e de fácil aplicação pelos agricultores familiares, para a melhoria e a sustentabilidade de sua produção. Há também a apresentação de receitas culinárias, de orientações sobre tecnologias simples ou práticas agrícolas que contribuem para a segurança alimentar e para o aumento da renda familiar. 
Cada programa tem 15 minutos de duração. No Brasil o rádio tem uma importância grande, considerando a dimensão continental e o forte aspecto de aprendizagem pela oralidade ainda presente no meio rural. O rádio chega aos locais mais distintos e possibilita que as informações orais disseminem e promovam a construção do conhecimento, especialmente para os agricultores e demais públicos com níveis diferentes tipos de letramentos.

\section{DVDs com reportagens do programa televisivo Dia de Campo na TV (DCTV)}

As reportagens do programa semanal da Embrapa, o DCTV, apresentam inovações tecnológicas, geradas pela pesquisa agropecuária e desenvolvidas pela Embrapa. O vídeo é um valioso apoio didático, em um contexto comunicacional afetivo, que facilita e predispõe os sujeitos a compreender mais facilmente as mensagens apresentadas, pois tem um formato do ponto de vista pedagógico que segue uma estrutura passo a passo, que permite uma compreensão clara, para a consequente utilização da tecnologia no cotidiano. Os programas abordam temas como cultivos, criações, meio ambiente, agroindústria, recursos genéticos, florestas, agroenergia, entre outros.

O uso dessas mídias como instrumento de apoio a ações pedagógicas, conforme se destaca nas capacitações de mediadores, exige estratégias diferenciadas, de acordo com a necessidade de cada seguimento de público, mas, em geral, sugere-se a formação de rodas de escuta para ouvirem os áudios dos programas ou assistirem aos vídeos, debaterem sobre o tema apresentado, a partir do olhar, dos saberes e vivências locais e, a partir de então, apresentarem propostas comuns para a melhoria do problema que enfrentam e cuja tecnologia abordada pode ajudar. 


\section{Títulos avulsos}

São publicações importantes com títulos e conteúdos variados, que buscam o aprofundamento de leituras diversas como agroecologia, hortaliças, áreas paradidáticas, receitas feitas com produtos agrícolas de modo geral, sobre meio ambiente, solos, entre outros, que são incluídos no kit das Minibibliotecas e que são inseridos de acordo com as necessidades identificadas em cada contexto e públicos contemplados.

$\mathrm{Na}$ apresentação dessas publicações, os capacitadores destacam para os mediadores a importância de contextualizar para a cultura e realidades locais com exemplos o tema apresentado, seja de um produto, de uma criação, ou de uma receita.

\section{Dinâmicas}

Esse é o momento do despertar. Trazemos textos de autores como Paulo Freire, Vygotsky, Rubem Alves, Hannah Arendt, Milton Santos, Frei Betto e outros diversos que falam da importância da leitura de mundo, do homem e dos livros.

A leitura verdadeira me compromete de imediato com o texto que a mim se dá e a que me dou e de cuja compreensão fundamental me vou tornando também sujeito. Ao ler não me acho no puro encalço da inteligência do texto como se fosse ela produção apenas de seu autor ou de sua autora. Esta forma viciada de ler não tem nada que ver, por isso mesmo, com o pensar certo e com o ensinar certo (Freire, 1996, p.27).

Há, entretanto, uma condição para que a leitura seja de fato prazerosa e válida: o desejo do leitor. Como afirma Pennac (1998 citado 
por Voltani, 2008) "o verbo ler não suporta o imperativo". Quando transformada em obrigação, a leitura se resume a simples enfado.

À medida que os textos vão sendo lidos, pelo grupo, normalmente pergunta-se quem gostaria de ler um pequeno texto, dependendo da voluntariedade para fazer a leitura na oficina, a partir daí escolhe-se alguns participantes da oficina e se distribui os textos de forma aleatória. Essas leituras funcionam de forma sutil como um termômetro, para que sejam avaliados o envolvimento, a capacidade leitora, a empolgação, a entonação, a postura, a dicção e os aspectos que fazem parte de uma boa leitura e, ao término de cada texto, sugere-se que o grande grupo fale sobre o que compreendeu do texto, de que forma ele contribuiu e que reflexões podem ser feitas a partir daquela leitura. Após esse momento começa a dinâmica "namoro com os livros".

\section{Namoro com os livros}

O namoro é o começo da culminância da oficina, onde se sugere que todos se aproximem do acervo, uma vez que, até então, eles só o observavam e, a partir daí manuseiem todos os títulos que chamaram a sua atenção no momento da apresentação.

No segundo momento, é sugerido que cada participante escolha uma mídia, impressa e/ou eletrônica que tenha uma ligação maior com a sua realidade. Feito isso, no terceiro momento sugere-se que façam pequenos grupos por afinidade de temas e/ou por áreas de trabalho para que discutam de que forma aquela obra pode contribuir para sua prática diária. A culminância se dá quando o grupo elege um representante para falar das obras escolhidas. Nesse momento, normalmente eles falam dos objetivos, possíveis projetos envolvendo as temáticas, e as possíveis estratégias que podem ser adotadas. É um momento muito rico com muitas ideias, sugestões, relatos de 
práticas diárias, propostas interdisciplinares e muita predisposição e comprometimento para possíveis parcerias.

\section{Avaliação da capacitação}

A avaliação da capacitação é feita por meio de um instrumento (questionário) semiestruturado, de análise qualitativa, onde cada sujeito envolvido tem o seu lugar de fala. Normalmente esses discursos são analisados com cuidado e rigor, onde são ponderadas as críticas e sugestões para compor a melhoria das práticas de capacitação.

\section{Metodologia}

Tendo em vista a implantação das Minibibliotecas, a realização das capacitações para o despertar do uso do conteúdo pelas comunidades e a posterior avaliação de uso desse acervo pelo público-alvo, foi realizada uma pesquisa qualitativa junto aos possíveis multiplicadores participantes das capacitações nos territórios da cidadania no Semiárido nordeste brasileiro, nos anos 2012, 2013 e 2014.

O Universo da pesquisa foram os 14 Territórios da Cidadania de atuação da Embrapa no Plano Brasil sem Miséria, situados no Semiárido brasileiro, quais sejam: Territórios de Cocais e Baixo Parnaíba - no Estado do Maranhão; Território do Inhamuns Crateús e Cariri - no Estado do Ceará; Território do Alto Oeste Potiguar, no Estado Rio Grande do Norte; Território de Irecê; Piemonte Norte de Itapicuru, e Velho Chico- no Estado da Bahia; Território do Vale do Rio Guaribas - no Estado do Piauí; Agreste Alagoano- no Estado de Alagoas; Território Borborema- no Estado da Paraíba; Território Alto Sertão Sergipano- no Estado de Sergipe; Território Serra Geral- 
no Estado de Minas Gerais. A amostra da pesquisa foi composta por 420 participantes das capacitações, tais como agricultores familiares, professores, alunos e extensionistas rurais.

No final da oficina o grupo faz uma autoavaliação oral, da participação, compreensão da metodologia, interação com o grupo e tudo mais que queiram falar. Posterior a esse momento é aplicado um instrumento avaliativo semi-estruturado para que cada um faça observações, contribuições e críticas, se for o caso. A técnica de análise adotada foi a análise de conteúdo por ser a mais coerente com as metodologias utilizadas.

A análise do conteúdo foi organizada em três fases: 1) A pré-análise foi realizada por meio da leitura desses discursos, onde selecionamos todas as falas que poderiam contribuir com o propósito da avaliação, que é reavaliar o processo a cada oficina. 2) A exploração do material se deu de várias formas, inclusão em relatórios, análises comparativas com o resultados de outras oficinas. 3) O tratamento dos resultados, a inferência e interpretação dos dados, estão nos quadros abaixo.

As variáveis analisadas por meio dos registros oriundos das auto avaliações orais dos participantes registradas nas cadernetas de campo e dos questionários aplicados foram: formação escolar dos multiplicadores, área de atuação, nível de satisfação, formas de utilização do acervo, expectativas da oficina, impressões, sugestões e críticas do acervo apresentado.

\section{Apresentação e discussão dos resultados}

No período de 2012 a 2014, foram capacitados 420 mediadores no uso das Minibibliotecas, provenientes dos 14 territórios localizados no Semiárido brasileiro, priorizados pelo Plano Brasil Sem Miséria (PBSM). Da sistematização dos questionários de avaliação 
sobre as oficinas de capacitação, destacam-se, a seguir, os mais relevantes para efeito dessa pesquisa.

Quanto à Formação Escolar, identificou-se que (47\%) dos participantes têm curso superior e, que (53\%) têm e/ou estão cursando a educação básica. Na metodologia da capacitação foram utilizadas estratégias diferenciadas para cada público, as quais não tiveram como critério para a participação nas capacitações o nível de escolaridade. Essa escolha exige a adequabilidade das informações sobre o conteúdo, ao nível de compreensão de cada sujeito do processo, sem prejuízo da qualidade da aprendizagem. Com relação à área de atuação, observou-se que a maioria dos mediadores é oriunda da área da educação, grupo pertinente e estratégico na formação de mediadores locais.

Cerca de $70 \%$ dos mediadores declararam ter pouco conhecimento sobre o acervo das Minibibliotecas até o momento da capacitação. Esse dado suscita a necessidade de ampliar a divulgação do projeto Minibibliotecas nos contextos locais, para promover maior acesso às informações tecnológicas contidas no acervo e estimular o diálogo de saberes, por meio de iniciativas locais de incentivo à leitura. Os discursos dos respondentes e as análises estão nos Quadros 1, 2,3 e 4, que seguem abaixo, onde foram destacadas as falas e as análises das mesmas, de acordo com a questão equivalente.

Quadro 1: Qual (is) atividade(s) fará usando o acervo da Minibiblioteca?

\begin{tabular}{|l|}
\hline \multicolumn{1}{|c|}{ Discursos dos participantes } \\
\hline "Oficinas e dias de campo e orientações aos agricultores familiares". \\
\hline "Divulgação do material na escola, pessoas da comunidade e agricultores". \\
\hline "Nas atividades de agroecologia, apicultura, caprinocultura e associativismo". \\
\hline "Multiplicar o conhecimento da minibiblioteca com os agricultores familiares, para \\
que melhorem os sistemas produtivos". \\
\hline "Em Rodas de leitura com agricultores da comunidade". \\
\hline "Trabalhar com agricultores na extensão rural". \\
\hline
\end{tabular}

Fonte: Dados da pesquisa, 2012/2013/2014. 
Quanto às atividades que serão realizadas usando o acervo da Minibiblioteca, as falas trazem as oficinas, o dia de campo e rodas de leituras, como possíveis espaços sociais onde o acervo das Minibibliotecas pode ser socializado. Observamos que as áreas de conhecimentos destacadas nos discursos foram: agroecologia, apicultura, caprinocultura e associativismo. O objetivo das atividades é divulgar o projeto nas escolas e na comunidade. Para Freire (2000, p.5) "Leitura boa é a leitura que nos empurra para a vida, que nos leva para dentro do mundo, que nos interessa viver".

Quadro 2: A oficina atendeu às suas expectativas?

\begin{tabular}{|l|}
\hline \multicolumn{1}{|c|}{ Discursos dos participantes } \\
\hline "Esclareceu diversas formas de trabalhar com a Mini na escola e na comunidade". \\
\hline "Nunca pensei que fosse tão bom, bastante explicito." \\
\hline "Despertou-me o desejo de buscar mais conhecimento sobre agricultura familiar, com \\
suas práticas sustentáveis." \\
\hline "O tempo foi curto para explorar melhor os temas propostos na programação." \\
\hline $\begin{array}{l}\text { "Ajudou muito a não cair na rotina por incentivar os participantes a contribuir de } \\
\text { alguma forma. Sugiro que se repita outras vezes." }\end{array}$ \\
\hline
\end{tabular}

Fonte: Dados da pesquisa, 2012/2013/2014.

De acordo com os multiplicadores, as expectativas de acordo com os discursos foram atendidas, pois esclareceram, despertaram o desejo de buscar mais conhecimentos sobre agricultura e práticas sustentáveis. "Não há ensino sem pesquisa e pesquisa sem ensino. Esses que fazeres se encontram um no corpo do outro [...] Ensino porque busco, porque indaguei, porque indago e indago-me." (Freire, 1996, p.29).

Quadro 3: Impressões dos participantes sobre o acervo d a Minibiblioteca.

\section{Discursos dos participantes}

"O livro não é feito para se guardar, mas para divulgar o conhecimento."

"O acervo contribuirá para a promoção da interação entre professores e alunos do campo" 
"As Minibibliotecas possibilitam pensar a educação no contexto da agricultura."

"O texto representa o enlace da educação com a agricultura, para que os livros e os projetos rurais sejam mais valorizados."

"Os livros são essenciais na vida de cada um. Às vezes, sequer sabemos a origem do nosso nome."

Fonte: Dados da pesquisa, 2012/2013/2014.

De acordo com os discursos os livros são essenciais na vida de cada um, e os textos representam o enlace da educação com a agricultura. As Minibibliotecas possibilitam pensar a educação no contexto da agricultura. Assim vemos que o ato de ler para Freire (1989).

A leitura do mundo precede a leitura da palavra, daí que a posterior leitura desta não possa prescindir da continuidade da leitura daquele. Linguagem e realidade se prendem dinamicamente. A compreensão do texto a ser alcançada por sua leitura crítica implica a percepção das relações entre o texto e o contexto (Freire, 1989, p.01).

Quadro 4: Sugestões ou críticas quanto ao acervo das Minibibliotecas.

\section{Discursos dos participantes}

"Foi produtiva. Cabe aos que participaram do curso multiplicar todas as informações e conhecimentos que foram adquiridos no curso Minibiblioteca."

"Metodologia dinâmica e enriquecedora está de parabéns a professora por sua capacidade e liderança e conhecimento do tema."

"A metodologia foi suficiente na compreensão, na teoria para colocar na prática; eu queria que essa oficina tivesse chegado há 10 anos muito bom, muito bom."

"Foi produtiva. Cabe aos que participaram do curso multiplicar todas as informações e conhecimentos que foram adquiridos no curso Minibiblioteca."

"Quero parabenizá-los pela iniciativa! Muito gratificante ter feito parte dessa equipe. Sucesso e muitas realizações para todos."

Fonte: Dados da pesquisa, 2012/2013/2014.

Ao analisar as falas sobre sugestões e críticas, percebemos que a metodologia da capacitação foi enriquecedora e dinâmica, muito 
em função do domínio dos conteúdos trabalhados, na condução da oficina, no saber ouvir e no mediar com equidade os diálogos.

Mas o que se sabe é que as informações e os exemplos a que se expõe sempre podem influenciá-los mais ou menos intensamente, talvez seja a porta de entrada para os educadores, nesse seu mundo tão particular, criando um meio propício; é oferecer, à inteligência, a argamassa, o material de construção em quantidade e qualidade suficientes para que o sujeito construa suas estruturas de pensamento da melhor maneira, com o melhor tipo de informação e os melhores exemplos possíveis, e a leitura pode ser um deles. (Araújo, 2009, p.19).

\section{Considerações finais}

A iniciativa de capacitar mediadores no uso das Minibibliotecas, no contexto do Plano Brasil Sem Miséria, surgiu como uma proposta pedagógica inovadora que articula a importância da leitura no contexto rural com a possibilidade de inclusão produtiva. As oficinas de capacitação de mediadores têm proporcionado o intercâmbio de saberes local e o maior acesso às informações tecnológicas entre os participantes. Além de, também, estimular a possibilidade de formação de uma rede de mediadores na região do Semiárido brasileiro com potencialidades de atuação conjunta nos processos territoriais de inclusão social e produtiva, bem como no fortalecimento do protagonismo dos sujeitos do campo, no acesso e/ou ampliação da participação destes nas políticas públicas específicas para o meio rural.

Considera-se que a proposta metodológica utilizada foi pertinente, face à diversidade cultural e produtiva existente nos contextos locais. As dinâmicas aplicadas estimularam processos dialógicos 
de reflexão sobre a importância da leitura e do uso do acervo das Minibibliotecas no contexto local, considerando também que as Minibibliotecas expressam em seus conteúdos, conhecimentos vivenciados no dia-a-dia das pessoas dessas comunidades.

Em doze anos de existência, as Minibibliotecas contemplaram mais de cinco mil escolas da rede formal e não formal de ensino, universidades, institutos federais, sindicatos de trabalhadores rurais, associações de agricultores, comunidades quilombolas e indígenas, além de outros espaços cujo objetivo principal é estimular a leitura e a inclusão produtiva no meio rural.

O processo de capacitação oportunizou a identificação de aperfeiçoamento da metodologia trabalhada no projeto, como, por exemplo, a possibilidade de criação de redes de contatos, fóruns ou comunidade virtual para a troca de experiências, formas de motivação das comunidades, levantamento de relatos de necessidades e outras informações de interesse das comunidades, sendo mais um canal de diálogo entre elas e a Embrapa. A observação e a análise dos resultados a curto, médio e longo prazo também contribuiram para esse aperfeiçoamento.

\section{Referências bibliográficas}

Araújo, M. F. L. de. et al. (2009). Avaliação do Projeto Minibiblioteca Semiárido do Nordeste e no Vale do Jequitinhonha, MG: uma Pesquisa-Ação. Brasília, DF: Embrapa Informação Tecnológica.

EMBRAPA, Secretaria de Gestão e Estratégia. (2008a). V Plano-Diretor da Embrapa: 2008-2011-2023. Brasília, DF: Embrapa.

EMBRAPA. (2012). Capacitação de mediadores para uso do acervo das Minibibliotecas: Roteiro sugestivo. Disponível em: http://hotsites. Sct .embrapa. br/ minibibliotecas /documentos/Cartilha_capacitacao_uso_minibibliotecas.pdf. Acesso em: 29 março de 2015.

MDS. (2009). FOME ZERO: Conceito 2006. Disponível em: <http://www.mds.gov. br/o_que_é>. Acesso em: 20 de julho de 2015.

Freire, P. (1989). A importância do ato de ler: em três artigos que se completam. São Paulo: Autores Associados. 
Freire, P. (1996). Pedagogia da autonomia do ato de ler. São Paulo: Ed. Cortez.

Freire, P. (2005). Pedagogia da autonomia: saberes necessários à prática educativa. São Paulo: Paz e Terra.

Gohn, M. da G. (2006). Educação não formal, participação da sociedade civil e estruturas colegiadas nas escolas. Ensaio: aval. pol. públ. Educ.,14(50), 27-38.

Goldenberg, M.(1998/2000). A arte de pesquisar: como fazer pesquisa qualitativa em Ciências Sociais ( $3 .^{a}$ edição). Rio de Janeiro: Record.

Orlandi, E. P. (2013). Análise do discurso e linguagem: significar com palavras é diferente de significar com silêncio. São Paulo: Globo Universidade.

Brasil (2002). Ministério da Educação. Secretaria da Educação Média e Tecnológica. Parâmetros Curriculares Nacionais (PCN) - Ciências da Natureza e suas Tecnologias. Brasília: MEC.

Brasil (2000). Ministério da Educação. Secretaria de Educação Média e Tecnológica. Parâmetros Curriculares Nacionais (Ensino Médio). Brasília: MEC.

Portal da Cidadania (2009). Territórios da Cidadania. Disponível em: <http://www. territoriosdacidadania.gov.br>. Acesso em: 10 de abril de 2015.

Voltani, G. G. \& Daniel, P. (2008). Na sala de leitura. Acolhendo alf. países líng. port. Revista USP, 2(4). Disponível em: <http://www.revistasusp.sibi.usp.br/ scielo. php?script=sci_arttext\&pid=S1980-76862007000200014\&lng=es\&nrm=iso $>$. Acesso em 20 de fevereiro de 2009.

Vygotsky, L.S. (1991). A formação social da mente. São Paulo: Martins Fontes.

Warschauer, C. (2001). Rodas em rede: oportunidades formativas na escola e fora dela. Rio de Janeiro: Paz e Terra. 